\title{
Retraction Note to: Immobilization of Heavy Metals in e-Waste Contaminated Soils by Combined Application of Biochar and Phosphate Fertilizer
}

\author{
Ling Huang • Chong Liu • Xiaowen Liu • \\ Zhiliang Chen
}

Published online: 28 May 2019

C) Springer Nature Switzerland AG 2019

\section{Retraction Note to: Water Air Soil Pollut (2019) 230: 26 \\ https://doi.org/10.1007/s11270-019-4081-5}

The authors have retracted this article. After publication they became aware that the data for cattle manure biochar reported in this article are actually data for rice straw biochar. The results, discussion and conclusions are therefore invalid. All authors agree with the retraction.

Publisher's Note Springer Nature remains neutral with regard to jurisdictional claims in published maps and institutional affiliations.

The online version of the original article can be found at https://doi.org/10.1007/s11270-019-4081-5

L. Huang $\cdot$ C. Liu $\cdot$ X. Liu $\cdot$ Z. Chen $(\bowtie)$

Ministry of Ecology and Environment, South China Institute of

Environmental Science, Yuancun West Street 7,

Guangzhou 510655, China

e-mail: 18826482520@163.com

L. Huang

e-mail: 1069636146@qq.com

C. Liu

School of Environmental Science and Engineering, Sun Yat-sen University, Guangzhou 510275, China 